\title{
A Critical Theory of Medical Discourse: Ideology, Social Control, and the Processing of Social Context in Medical Encounters*
}

\author{
HOWARD WAITZKIN \\ University of California, Irvine
}

Journal of Health and Social Behavior 1989, Vol. 30 (June):220-239

The personal troubles that patients bring to doctors often have roots in social issues beyond medicine. While medical encounters involve "micro-level" interactions between individuals, these interpersonal processes occur in a social context shaped by "macro-level" structures in society. Examining prior theories pertinent to medical discourse leads to the propositions: (a) that medical encounters tend to convey ideologic messages supportive of the current social order; (b) that these encounters have repercussions for social control; and (c) that medical language generally excludes a critical appraisal of the social context. The technical structure of the medical encounter, as traditionally seen by health professionals, masks a deeper structure that may have little to do with the conscious thoughts of professionals about what they are saying and doing. Similar patterns may appear in encounters between clients and members of other "helping" professions. Expressed marginally or conveyed by absence of criticism about contextual issues, ideology and social control in medical discourse remain largely unintentional mechanisms for achieving consent.

Why look at medical encounters from a theoretical point of view?

* Direct all correspondence to Howard Waitzkin, UCI/North Orange County Community Clinic, 300 West Romneya Drive, Anaheim, CA 92801.

This article is one of a series of papers from an ongoing research project on medical discourse. The research has been supported in part by grants from the National Center for Health Services Research (HS-02100), the Robert Wood Johnson Foundation (through the Clinical Scholars Program), the Fulbright Program, the National Institute on Aging (1-F32-AG05438), and the Academic Senate of the University of California, Irvine (Honorary Faculty Research Fellowship). During a span of many years, John Stoeckle, Elliot Mishler, Sam Bloom, members of the primary care research discussion group at the University of California, Irvine, and participants in the Society of General Internal Medicine have given me constructive suggestions about the project. Stephany Borges, Theron Britt, J. Hillis Miller, Mark Poster, Leslie Rabine, and John Carlos Rowe have helped in my attempts to negotiate the terrain of critical theory in the humanities. My errors are no fault of theirs.
More than a quarter century ago, C. Wright Mills analyzed the relationships between "personal troubles" and "social issues." Mills pointed out that the troubles a person experiences arise in the context of broader social problems. According to Mills, an individual's difficulties are almost always interconnected with structures in society, although these links may not be obvious on the surface. Mills argued that an important goal for people concerned with social problems - those with what he called the "sociological imagination" - is to clarify how personal troubles and social issues relate to one another (1959, pp. 3-24).

In the intimacy of the medical encounter, patients present to their doctors a variety of personal troubles. From Mills' perspective, these troubles often have roots in social issues that go beyond the individual level. Yet the social issues themselves tend not to receive critical attention in conversation between patients and doctors. In trying to help their patients, doctors often find ways that patients can adjust to troubling social conditions. ${ }^{1}$ 
Seen from this vantage point, medical encounters are "microlevel" processes that involve the interaction of individuals. These interpersonal processes, however, occur in a social context, which is shaped by "macrolevel" structures in society. For example, when patients and doctors discuss problems at work, they take their bearings from the organization of work in society, social expectations about work, social class relations pertaining to work, and so forth. Similarly, when problems pertaining to family life arise in medical encounters, the conversation must deal in some way with such issues as women's and men's roles in the family, expectations about reproduction and the maintenance of households, and social patterns affecting children, elderly people, and individuals at different stages of the life cycle. Patients also raise other kinds of social problems when they talk with their doctors, and macrolevel structures in the society shape the context of those problems as well.

One challenge for social theory has been to clarify how macrolevel social structures and microlevel processes affect one another. Many schools of thought have dealt with this theoretical challenge. Some theorists have argued for the importance of macrolevel structures like social class and political power in determining what happens in interpersonal processes at the micro level. Others have claimed that microlevel processes are primary, and that macrolevel structures emerge only as a reflection (similar terms include integration, aggregation, gloss, repetition, and transformation) of microlevel processes occurring routinely in everyday life. A compromise position holds that macrolevel structures profoundly influence interpersonal processes, but that microlevel processes cumulatively reinforce social structures at the macro level as well (for a critical review, see Knorr-Cetina and Cicourel 1981).

In this paper, I do not hope to resolve this theoretical debate, but rather to explore how the macro and micro levels impinge on each other in the single institutional sphere of medicine. When patients and doctors talk with each other about social problems, their words have much to do with the social order around them. Structures of society help generate the specific social context in which patients and doctors find themselves. The talk that occurs in medical encounters also may reinforce broader social structures. Similar patterns probably occur in the communication between clients and members of other helping professions, such as law, psychology, and social work. Clarifying these patterns in medicine therefore sheds light on professionalclient discourse more generally. In exploring the interconnections between personal troubles and social issues, and between the micro and macro levels, I first build on the work of prior theorists to deal with the issue of medical ideology. I then examine social control by professionals in their encounters with clients. Afterward, I ask how the language of medical encounters pertains to the social context of medicine.

\section{MEDICAL IDEOLOGY}

Ideology, while difficult to define, is in general an interlocking set of ideas and doctrines that form the distinctive perspective of a social group. Through such ideas and doctrines, ideology represents - on an imaginary level-individuals' relationship to the real conditions of their existence (cf. $\mathrm{Al}$ thusser 1971, pp. 162-165; a critical appraisal of Althusser's contribution follows later in this paper). This imaginary quality of ideology, which patterns how individuals perceive and interpret their experience, contributes to ideology's impact in society. Because it helps shape a population's perceptions and interpretations, ideology can achieve a most profound effect on social life.

As a macrolevel structure in society, ideology impinges on patients and doctors as part of the social context of medical encounters. At the micro level of interpersonal interaction, elements of ideology appear in doctor-patient communication. What patients and doctors say when they meet reinforces their particular ideologic conceptions about social life. Although ideology has received wide attention in social theory, several previous theoretical contributions are helpful for clarifying ideology in medicine. In presenting these perspectives on ideology, I emphasize those theoretical strands that shed light on ideologic processes in medical encounters.

Ideology, work, and the family: perspectives from early Marxist theory. In classic Marxist theory, ideology is an important though inconsistently developed notion. According to the principle of economic determi- 
nacy, the events of history emerge chiefly from economic forces and the conflicting relations of social class. From this viewpoint, economic forces affect the ideologies of a specific historical period. Despite the primacy of economic forces, ideology is crucial in sustaining and reproducing the social relations of production, especially patterns of domination. Marx called attention to the mechanisms by which ideology reinforces capitalist relations of production and the interests of the capitalist class (1894, pp. 370-90, 790-94). While ideologies arise in many different areas, including religion, aesthetics, and politics, early Marxist analyses did not discuss in depth the ideologic components of medicine (Marx and Engels 1846, pp. 3-78).

The Marxist perspective, however, leads to questions about how elements of ideology in medical encounters relate to economic behavior. Ideologic conceptions of work, as they are transmitted in doctor-patient interaction, reflect more general ideologic notions about economic activities in a given society. When they are spoken in medical encounters, these notions reinforce a society's dominant ideologic conceptions about the nature of work and of economic production.

For instance, among the many definitions of "health" that have appeared during the twentieth century, modern medicine has emphasized in practice an interpretation of health as ability to work. There are several ways that this definition of health has been reinforced and diffused in the population. The public health policies that large philanthropies and government agencies have initiated in the United States and other countries consistently have emphasized the importance of a healthy work force (Brown 1979, pp. 112-34; Franco-Agudelo 1983). Images of health conveyed by the mass media also have supported the symbolism of health as the capacity to do productive work (Kelman 1975). These images have communicated a message that the healthy person is one who produces economically. Moreover, a widely touted standard by which to judge medicine's cost-effectiveness is its contribution to patients' subsequent work productivity (Weinstein and Stason 1977).

Doctor-patient interaction, I will argue, reinforces this same definition of health as the ability to work. In certain encounters with patients, doctors communicate explicitly or subtly a message that work is preferable to idleness. When people become sick, they often stop working, and doctors get involved in this process in several ways. Frequently doctors certify that a patient is physically disabled and thus unable to work. By the certification of disability, a doctor in effect decides when a patient must return to the job. When judging the seriousness of a patient's complaints, a doctor investigates whether the patient's problems interfere with work. Doctors write letters to employers, insurance companies, and government agencies about patients' work limitations and discuss this correspondence to a greater or lesser degree with the patients themselves. During their routine talk with patients, doctors inevitably convey attitudes about work, usually to encourage patients' continued performance on the job. In these instances and many others, the impact of the doctors' words is to define health as the capacity to work productively.

The family becomes a second important focus for ideologic elements in medical encounters, and theorists in the Marxist tradition have emphasized the connections between the family and economic production. For example, Engels claimed that the family, by "propagation of the species," plays a key role in reproducing the labor force. Women's subordinate position in the family, according to Engels, helps maintain the family's reproductive role (1891). However, the family's importance goes beyond the physical reproduction of labor. The family also helps reproduce the ideologic framework of the economic system. For instance, patterns of sexuality and child rearing in the family reinforce personality characteristics and attitudes that tend to accept hierarchies of class and authority. By sustaining such patterns, Engels argues, the family becomes an important institution for ideologic reproduction, which helps achieve the population's acquiescence to and participation in current relations of economic production.

Medicine also mediates the family's reproductive role. As noted already, medicine tends to define health as the ability to work. However, a secondary and related definition is that health is the ability to reproduce labor. Women's activities as homemakers, wives, and mothers are crucial in the family's reproductive activities. Even when women do not work outside the home, they often care for working husbands and for children who later will take part in production and 
reproduction. Although a greater proportion of women have entered the labor force since World War II, they still face the social expectation that they remain primarily responsible for these reproductive activities. That is, "healthy" women do these things, and doctors predictably help many women in sustaining their reproductive capabilities. For their male clients, doctors also may interest themselves in the stability of family relations. For both men and women, adequate functioning in familial responsibilities thus becomes another criterion in doctors' assessment of health. As discussed later in this paper, doctors are among the expert professionals who increasingly have regulated family life during the twentieth century. How doctorpatient interaction conveys ideologic notions about family life is a question of some interest.

Later theories of ideology. The examples of work and the family lead to a consideration of how certain other theorists-Gramsci, Lukacs, Althusser, and Habermas-have treated the question of ideology. A unifying theme among these theoretical positions, all of which are influenced by classical Marxism, is that ideology serves as a subtle mechanism which helps win a population's consent to the ways a society is organized. These theorists also emphasize that ideology helps maintain the economic system and that supporting institutions like the family are key elements in reproducing a society's dominant ideologic patterns. Although the theorists to be considered do not deal specifically with medical encounters, one purpose of reviewing these theories is to apply them to the question of ideology in medicine.

From Gramsci's viewpoint, groups in power use two types of sociopolitical control to maintain and reproduce relations of economic production (1971, p. 123-202, 375-77, 406-7). In the first place, there is direct coercion; by holding the legal means of violence-in the armed forces, police, prisons, courts, and related institutions - the state protects the established order partly through force and repression. However, Gramsci claims, no regime can hold power for long periods of time strictly by authoritarian rule.

Ideologic hegemony, according to Gramsci, is a second and ultimately more important mechanism of control. Such institutions as the schools, churches, mass media, and family inculcate a system of values, attitudes, beliefs, and morality. This ideologic system supports the established order and the class interests that dominate it. The same ideologic forces achieve consent and mute resistance from disadvantaged groups.

While Gramsci did not consider medicine's ideologic impact, a similar theoretical perspective would ask to what extent medicine reinforces the dominant ideologic system of a society. When doctors convey ideologic notions about desirable behavior, especially as these notions help shape patients' roles in work and the family, medical encounters contribute to the broader hegemonic impact of ideology. In this sense, medicine exerts ideologic effects that parallel those of such institutions as schools, churches, and the mass media.

Lukacs' conceptions of class consciousness and reification also are pertinent to medicine's ideologic impact. Regarding class consciousness, Lukacs, like Gramsci, explores how a society's dominant ideologies are conveyed and reinforced. In discussing literature and other forms of cultural expression, Lukacs emphasizes the ways that these materials both reflect and strengthen broad ideologic patterns (1971a, pp. 46-222; 1971b; Jameson 1971b; Taussig 1980). According to Lukacs, such ideologic patterns shape the consciousness of individuals and, cumulatively, of social classes. In this process, the totality of social relations in an entire society becomes mystified and blocked from conscious thought. Reification, Lukacs argues, involves the transformation of social relations into things or thing-like beings that take on their own separate reality in people's consciousness. Shaped by ideology, consciousness focuses on the concrete problems and objects of everyday life, especially economic commodities, rather than on the totality of social relations that lies behind these routine concerns. Attention becomes focused on the concrete objects of daily life, and in this process of reification the totality of social relations escapes conscious attention.

Reification contributes to medicine's impact. In medical encounters, technical statements help direct patients' responses to objectified symptoms, signs, and treatment. This reification shifts attention away from the totality of social relations and the social issues that are often root causes of personal troubles. Instead, attention gets paid to problems of individual pathophysiology and personality. 
By reifying problematic social relations, medicine reduces the potentiality for effectively criticizing those relations. Symptoms, signs, and treatment take on an aura of scientific fact, rather than subjective manifestations of a troubled social reality. The medical processing of social problems invests them with the symbolism of objects, relatively immune from criticism or change. This same process constricts the level of attention to the disturbed individual, rather than social structures impinging on the individual. For instance, when the organization of work or tension in the family creates personal distress, expression of that distress in a medical encounter tends to reify the social structural roots of the problem. Under these circumstances, it is the objectified symptom or sign that requires treatment-not the institutional sources of individual distress.

Influenced by Gramsci and Lukacs, Althusser further analyzes the structures of control in modern societies. Althusser considers the interconnections among repressive and ideologic institutions, as well as their relationships to government (1971). Repressive state apparatuses (RSAs), Althusser argues, include the army, police, prisons, courts, and other institutions that maintain control through violence or repression. Ideologic state apparatuses (ISAs) are institutions that instill dominant ideologies in the population. In Althusser's analysis, ISAs include the family, legal system, electoral politics, mass media and communication systems, education, and cultural systems. RSAs are not purely repressive, nor are ISAs purely ideologic. Ideologies often legitimate the actions of RSAs. For example, justice and equality are ideologic notions that legitimate the functioning of the courts. Similarly, ISAs may use punishment for discipline, such as physical force or other forms of sanctioning that occur in the family or school system. Althusser argues that ISAs are especially important in reproducing class structure and the relations of economic production. According to Althusser, many social institutions-particularly the educational system-promulgate ideologies that assure the population's acquiescence and participation in productive work.

Althusser's analysis of the wide-ranging repressive and ideologic effects of many institutions in society, though controversial, pertains to medicine as well. In rare instances, medicine exerts directly repressive effects-as when physicians helped implement policies of genocide in Nazi concentration camps. Less obvious instances of medicine's repressive impact include doctors' roles in involuntary mental hospitalization, prison health care, capital punishment (in some cases administering lethal injections or otherwise assisting in executions), involuntary sterilization, and so forth.

Medicine's ideologic impact, however, is doubtless much more important than its repressive role. In their encounters with patients, doctors may interpret personal problems and encourage individual behaviors in directions that are consistent with the society's dominant ideologic patterns. From the perspective of Althusser's theory, when medical encounters convey a definition of health as the ability to work, they encourage workers' participation in economic production. Doctor-patient interaction also predictably transmits notions about family life that strengthen the family's ideologic impact. In these ways, medicine exerts ideologic effects consistent with those of other institutions like the educational system and mass media.

Another quite different theoretical approach also pertains to medical ideology. The "critical theory" of Habermas and other analysts of the Frankfurt School provides a link between ideology and science-and by extension, scientific medicine. Although Habermas's and Althusser's theories both have roots in classical Marxism, these two schools of thought diverge in fundamental ways. In particular, the Frankfurt School usually assumes that individuals have the capacity to reflect critically about society and to take "purposive" political action; Althusser diminishes the potentiality for effective criticism and political action by individuals. Both approaches, however, emphasize the impact of ideology. While Althusser focuses on the ideologic effects of various social institutions in reproducing the relations of production, Habermas stresses the ideologic components of science.

For Habermas, science is ideology par excellence precisely because it claims to be above ideology, that is, objective and value neutral (1970). Habermas argues that scientific ideology has defined an increasing range of problems as amenable to technical solutions. In this way, scientific ideology tends to depoliticize these social issues by removing them from critical scrutiny. According to 
Habermas, science legitimates current patterns of domination, including the class relations of production:

Technocratic consciousness is, on the one hand, "less ideological" than all previous ideologies. ... . On the other hand today's dominant, rather glassy background ideology, which makes a fetish of science, is more irresistible and farther-reaching than ideologies of the old type. For with the veiling of practical problems it not only justifies a particular class's interest in domination and represses another class's partial need for emancipation, but affects the human race's emancipatory interest as such $(1970$, p. 111).

What are the specific processes by which scientific ideology provides legitimation? One problem in Habermas' account is that it remains on an abstract level and rarely grounds theoretical claims in empirical reality. Habermas conveys an impression that scientific ideology creates legitimation through cultural symbols in the mass media, educational system, and technical organization of the workplace. He also argues that ideology and domination appear in the face-to-face interaction of individuals. Distorted communication, Habermas argues, arises in both the macrolevel realm of politics and the microlevel realm of interpersonal relationships. Domination creates distortion in communication, and undistorted communication is impossible, according to Habermas, under conditions of domination $(1970$, p. $113 ; 1971, \mathrm{pp}$. 214-73; 1974, pp. 1-40, 195-282; 1975, pp. 33-96; 1985, pp. 273-337). In a major part of his project, Habermas encourages resistance against domination and aims toward the creation of new, less distorted forms of communication. Concrete examples of scientific ideology, however, rarely appear in Habermas' work; for this reason, his account remains abstract and utopian regarding directions of change. On the other hand, his analysis causes one to look for specific instances of scientific legitimation and distorted communication in face-to-face interactions.

These considerations are pertinent to medical encounters to the extent that doctor-patient interactions convey ideologic messages under the rubric of scientific medicine. From Habermas' perspective, such messages legitimate current problems in society and further depoliticize these issues by deflecting critical attention from them. In addition, medical interactions show features of distorted communication, fostered for instance by devices of language that reinforce professional domination. In actual encounters between patients and doctors, then, one can ask how and to what extent medical discourse transmits scientific ideology.

\section{PROFESSIONAL SOCIAL CONTROL}

Social control-again to offer a simple definition of a complex concept-refers to mechanisms that achieve people's adherence to norms of appropriate behavior. In medicine, ideology and social control are closely related. When doctors transmit ideologic messages that reinforce current social patterns - at work, in the family, and in other areas of life-they help control behavior in ways that are defined as socially appropriate.

Dealing with problems outside the narrow realm of technical medicine tends to "medicalize" a wide range of psychological, social, economic, and political problems. Historically, numerous areas gradually have fallen under medical control. Examples include sexuality and family life, work dissatisfaction, problems of the life cycle (including birth, adolescence, aging, dying, and death), difficulties in the educational system (learning disabilities, maladjustment, and students' psychological distress), environmental pollution, and many other fields. By participating in these areas, practitioners often believe that they are extending the caring function of the medical role.

On the other hand, medicalization has become the subject of a critique that focuses on heath professionals' expanding role in social control (Conrad and Schneider, 1980; Ehrenreich and Ehrenreich 1978; Fox 1977; Illich 1975; Waitzkin 1971, 1983; Waitzkin and Waterman, 1974; Zola 1972, 1975, 1983). As medical management of social problems has increased, the societal roots of personal troubles become mystified and depoliticized. That is, by responding in limited ways to some of patients' nontechnical problems, medical practitioners tend to shift the focus of attention from societal issues to the troubles of individuals.

The history of professional social control: Foucault. The intrusion of the scientific 
discourse into many areas of social life has preoccupied Foucault in his work on the history of the professions. Through his studies of what he calls the human sciences, Foucault has conveyed the connections between knowledge and power (1980). According to Foucault, as such professions as medicine, psychology, law, and social work have developed, they have taken on positions of control in everyday life. By describing the political role of the human sciences, Foucault has clarified how professional social control emerged historically.

While Foucault's early work traces the history of medicine's diagnostic and therapeutic ideas (1975), his more recent studies emphasize how professional control has widened into everyday life (1977). Although modern punishment is more hidden than prior techniques like torture and public execution, Foucault argues, it orients itself to surveillance and professional control over the deviant population. Through new technologies of power, according to Foucault, the criminologic profession could create what appeared to be a humane reform over prior forms of gross corporal punishment. Further, he argues, the administrators of penal institutions have achieved surveillance of people who deviate from society's expectations about appropriate behavior.

Most important from Foucault's viewpoint, criminology has become a standard for professional practices throughout society. According to Foucault, similar technologies of surveillance also have emerged to achieve professional power in mental institutions, hospitals and clinics, workplaces, and schools. Foucault's examples show that social control has become more subtle, professionalized, and oriented to surveillance of deviant behavior.

Although Foucault's studies of prisons touch on medicine mainly by analogy, his work on sexuality pertains directly to medical encounters (1978). Foucault's colorful account of modern sexuality begins in the seventeenth century. Until that time, Foucault argues, religious institutions took an interest in sexuality, mainly through the confessional. When people confessed their sexual activities, priests commented on what liaisons and positions were appropriate and what actions required penance. After the Reformation and Counter Reformation, according to Foucault, concern gradually shifted from bodily activi- ties to thoughts, fantasies, intentions, and other mental processes related to sexuality. Especially during the nineteenth century, Foucault notes, surveillance and regulation of mental processes pertaining to sex became a preoccupation of science and particularly medicine. Professional practitioners then assumed a measure of control over the activities and psychological meanings of sexual life.

In discussing sexuality, Foucault emphasizes professional discourse and links discourse to power. That is, what professionals have said about sexuality has deepened professional power in everyday life (1978, pp. 101-102). What previously was a concern for the clergy has become a challenge for professionals, who assume various degrees of control over their clients' sexual expression. Medical doctors mediate sex, according to Foucault, but so do psychoanalysts, social workers, educators, bureaucrats in social welfare agencies, and other professionals who lay claim to expert knowledge. The discourse through which professionals communicate their special knowledge, from Foucault's perspective, enhances their ability to intervene in and to control others' behavior.

Where does one find such professional discourse? Foucault of course looks for discourses on sex in the books, articles, and other documents that professionals have written and published. However, for Foucault, unpublished discourse becomes as important as publications in achieving professional power, if not more so. For this reason, a variety of materials are appropriate sources for study. These sources include the brochures and files of medical institutions treating sexual disorders, the records of public welfare bureaucracies, therapists' notes, and professional correspondence concerning individuals who are considered deviant. Perhaps most important for the purposes here, one also may look for such discourse, whenever possible, in the face-to-face talk of professionals and their clients. Predictably, for instance, what doctors say to their patients about sex comprises a concrete expression of professional discourse and its power in daily life, probably to a greater extent than what doctors write about sex in textbooks and scientific articles (Poster 1984, pp. 131-32). Although Foucault alludes to the usefulness of oral materials, however, he does not use them himself in developing his arguments.

On the unintentionality of medical social 
control. As noted earlier, social control in medicine is generally an unintended process, dimly if at all perceived by participants in doctor-patient encounters. Health professionals seldom consciously view their activities as contributing to social control. In listening to words of distress from their clients, doctors usually do not see their responsibility as preserving the current organization of economic production or the stability of the family. Nonetheless, by focusing on individual troubles rather than social issues, doctorpatient encounters may reinforce the social order as presently constituted. Why do these processes tend to occur without the participants' conscious awareness?

To help explain the unintentionality of medical social control, one may look first to the class origins and position of health professionals. Since the beginning of the twentieth century, the vast majority of doctors have come from upper-middle-class families. In 1920,12 per cent of North American medical students came from working-class families, and this percentage has stayed almost exactly the same until the present time (Ziem 1977). The extremely limited recruitment of doctors from working-class families has persisted despite recent increases in the proportion of women and racial minorities entering the profession. For the small numbers with working-class roots, as for the rest of the profession, the acquired class position of physicians is one of relative privilege. Their predominantly comfortable lifestyle does not encourage professionals to criticize the social structural roots of their clients' distress, especially the sources of suffering in class structure. Instead, professionals' life experiences predictably leads them to help clients adjust to things as they are.

Professional education and socialization further contribute to the unintentionality of medical social control. A critique of power in society is, needless to say, seldom part of the medical school curriculum. On the contrary, professionals in training receive many lessons about individual pathophysiology and treatment. Within progressive instructional programs, trainees hear information about emotional disturbance and social problems. This training, however, consistently emphasizes the importance of psychological and social knowledge in responding to the needs of the individual patient. Such an approach seeks to help the patient cope with stresses arising in work, the family, and other key institutions. It does not, even in its more progressive and enlightened versions, foster social criticism or social change as part of the medical mission.

There are also situational constraints that leave medical social control below the level of consciousness. When a client is in trouble, a professional usually feels that something should be done. Yet the professional also senses the limits of what he or she as an individual can do. For instance, when a patient's symptoms reflect stress at work, a doctor tends to feel that changing the workplace is beyond the responsibility or even the capability of the medical role. With rare exceptions, such as those involving physical abuse, disruption of familial relations is not an appropriate goal of medical intervention. Wanting to help but unable personally to change the social structure, a health professional typically seeks a solution within the existing institutional context. Relaxation techniques, tranquilizers, counselling, family therapy, and related methods are all feasible approaches for the professional who wants to do something. For a patient in crisis, a doctor cannot do everything. What can be done tends to encourage coping and accommodation. Conscious recognition of these choices, or consideration of more critical alternatives, seldom occurs.

These situational constraints contribute to the generally conservative effects of the medical role. On the one hand, medical discourse usually does not attend to institutional causes of suffering. This orientation leads health professionals to overlook social change as a possible therapeutic option. On the other hand, when doctors do consider institutional problems in their encounters with patients, this intervention frequently serves to support the status quo. When a professional encourages mechanisms of coping and adjustment, such communication conveys a subtle political content. By seeking limited modifications in social roles-at work and in the family, for instance - which preserve a particular institution's overall stability, the practitioner exerts a conservative political impact. Despite the best conscious intentions, the practitioner thus helps reproduce the same institutional structures that form the roots of personal anguish. This contradiction is one source of pathos in the helping professions.

Medical social control also involves the management of potentially troublesome emo- 
tions. Doctors, for instance, regularly deal with patients' anger, anxiety, unhappiness, social isolation, loneliness, depression, and other emotional distress. Often these feelings derive in one way or another from patients' social circumstances, such as economic insecurity, racial or sexual discrimination, occupational stress, and difficulties in family life. Such emotions, of course, are one basis of political outrage and organized resistance. How health professionals manage these sentiments is an interesting question. One of medicine's effects may be the defusing of socially caused distress. Medicine is not the only institution in which such processes occur, nor do these phenomena necessarily occupy a major part of medical encounters. Still, it is worth asking how such largely unintentional microlevel processes take place. This question leads us to an analysis of the structure of doctor-patient interaction.

\section{THE TRADITIONAL FORMAT OF THE MEDICAL ENCOUNTER}

The traditional format of the medical encounter is as follows:

Chief complaint (CC) $\rightarrow$ present illness (PI) $\rightarrow$ past history (PH) $\rightarrow$ family history $(\mathrm{FH}) \rightarrow$ social history $(\mathrm{SH}) \rightarrow$ systems review (SR) $\rightarrow$ physical examination (PE) $\rightarrow$ other investigations (OI) $\rightarrow$ diagnosis $(\mathrm{Dx}) \rightarrow$ plan (P).

During a typical encounter, the doctor tries to cover some or all of these components in his or her spoken interaction, and by examination of the patient. In addition, the doctor provides a written version of the encounter, in the medical record. There, the doctor usually labels each component of the encounter with the same abbreviations that I am using here. This traditional format appears in most textbooks that provide instruction on clinical methods for trainees and practitioners of medicine. Research on doctor-patient communication, reported previously, has confirmed that medical practitioners actually do use the traditional structure as an organizing framework for their encounters with patients (Waitzkin 1985). ${ }^{2}$

To define and to comment on each of these elements, I will focus first on the components of the medical history $(\mathrm{Hx})$, which comprises $\mathrm{CC}, \mathrm{PI}, \mathrm{PH}, \mathrm{FH}, \mathrm{SH}$, and SR in the above scheme. In the chief complaint (CC), the physician elicts what is bothering the patient, in the briefest possible terms. The physician leads into the chief complaint usually with an opening question like: "Hello, what brings you in today?" or "Well, what's bothering you today?" or "How can I help you?" To these or similar questions, the patient might answer, "Headaches" or "My back hurts" or "I've got pain in my chest" or "I can't sleep" or "I want a check-up" and so forth. In asking for the $\mathrm{CC}$, the physician seeks to elicit the patient's foremost concern.

Through the present illness (PI), the patient elaborates on the chief complaint. He or she tells the doctor when the problem began, what the specific characteristics of the symptom might be, which medications or other measures relieve the symptoms, what prior medical attention he or she has received for the problem, and similar details that may contribute to the doctor's attempts to reach a diagnosis. Guiding the patient to elicit the CC and PI purportedly is the greatest skill that doctors develop in taking a medical history; some commentators argue that this is the most important skill in medicine. Doctors in training presumably learn a comfortable and effective balance between open-ended listening to the patient's story and more directive questioning that clarifies the patient's problem in terms of medical diagnoses.

Interruptions by doctors commonly begin to occur during the PI. Such interruptions basically are attempts to cut off story-telling by patients, for the following reasons (among others): the story may not contribute to a doctor's cognitive process of reaching a diagnosis; the patient's version of the story may be confusing or inconsistent; telling the story may take more time than is perceived to be available; or parts of the story may create feelings that are uncomfortable for the doctor, the patient, or both. The circumstances under which the doctor interrupts the patient's story to focus the PI (that is, what is interrupted, when it is interrupted, what reason is given for the interruption, and so forth) are important, especially to the extent that they cut off concerns about the social context of the medical encounter. Predictably, the PI is a critical juncture, during which certain elements, though they may be quite important in the patient's experience, come to be excluded from discourse, while other elements are included. 
What is the relationship between the spoken PI and the version that the doctor writes in the medical record? While writing a comprehensible PI may involve skillful effort by a doctor, its orderliness invariably gives a false sense of what happens during the spoken PI. For example, the doctor never writes, "I interrupted the patient at this point," or "I thought the patient's comments about his family here weren't pertinent to his pain, so I asked him about what medications he was taking," or "I was in a hurry to get my daughter from child care so I cut off the patient at this point," and so forth. Instead, the written PI represents the doctor's interpretation of a disorderly series of spoken exchanges. The orderliness of the written version belies what actually gets said during the PI, which is my chief focus here. This is not to say that the written PI is uninteresting, and others have documented the enormous differences in content between the spoken and written versions (Zuckerman, Starfield, Hochreiter and Kovasznay 1975). I am mainly concerned, however, with the spoken PI in all its disorderliness.

While the CC and PI are almost always present in medical encounters (assuming the patient is awake and conversant), other components may appear or not, depending on time, the doctor's desire to complete a comprehensive evaluation, financial issues such as the patient's insurance and how extensive an evaluation it permits, and other situational constraints. A doctor may choose to defer some or all the remaining components to future visits, or not cover them at all, although there is usually some attempt initially to develop a diagnosis and plan.

In the past history (PH), the doctor gathers information about past medical events in the patient's life that are not directly pertinent to the PI. These events typically include prior hospitalizations and surgery, other major illnesses, medications, allergies, immunizations, smoking, drinking habits, and recreational substance use.

The family history (FH) includes data about illnesses and deaths in the patient's immediate family: mother, father, sisters, brothers, spouse, and children. Additionally, in this section many doctors routinely elicit information about family occurrences of cancer, heart disease, hypertension, diabetes mellitus, and other common problems that may carry an increased risk in certain families.

Although one might expect the social history (SH) to be important for a contextual analysis of medical encounters, it is usually a perfunctory listing of demographic data. For instance, the doctor typically asks about birthplace, occupation, educational attainment, living situation, and insurance status. The contextual concerns that pertain to a patient's distress usually appear, subject to interruption and cut-off, during the PI, rather than the SH. In the SH itself, the doctor traditionally tends not to pursue in much depth how the patient's social circumstances might relate to the difficulties for which he or she is seeking medical attention.

Presumably, the systems review (SR) elicits any additional information about the patient that might be left out or missed by other parts of the history. The SR is sometimes very brief and sometimes quite lengthy; scuttlebutt among medical practitioners has it that the SR's length is inversely related to clinical experience. The expectation, however, is that the doctor will ask the patient whether he or she has experienced symptoms in more or less each of the following organ systems: skin, lymph nodes, head, eyes, ear, nose, throat, neck, respiratory system, cardiovascular system, gastrointestinal system, genitourinary system, reproductive system, neurologic system, endocrine system, and bones and joints. For instance, under the gastrointestinal system, the doctor would question about symptoms of the esophagus (principally swallowing), stomach (heartburn, ulcers, cancer, and so forth), duodenum, small intestine, large intestine (irregularity in bowel habits, bleeding, infections), rectum (hemorrhoids, fissures, bleeding), liver (jaundice, hepatitis, toxic exposures), and pancreas. In other words, the SR can be quite exhaustive, even more so if the patient happens to be a "yea-sayer." Then, doctor and patient enter potentially endless labyrinths of questions and answers, leading to frustrating excursions through a welter of symptoms and diseases that have little to do with the current purposes of the medical encounter. Gradual recognition of these pitfalls during a medical career accounts for the exhaustive efforts that medical students devote to the SR, while their supervising physicians often truncate the SR to a very brief series of questions, for which they do 
not expect to hear "yes" as a frequent answer.

The physical examination (PE) involves the laying on of hands, whose impact in medicine has been so highly touted. Without intimate touch, medical encounters would not differ nearly so much from other types of professional-client interactions. If time is available and if it has not already been done, a doctor will examine the body's entire external surface during the PE, as well as its internal orifices. When time is not available, or if the doctor is not inclined toward comprehensiveness, he or she does a more focused PE, concentrating on those parts of the body that might be related to the CC and PI.

After the PE, the doctor sometimes initiates one or more other investigations (OI)-lab tests, $\mathrm{x}$-rays, electrocardiograms, and so forth-whose purported aim is to clarify the diagnosis or to gather data that may be useful for treatment or prevention. OIs also seem to communicate something. They may convey an impression of thoroughness and concern. A scientifically oriented intervention may be reassuring because of the technical knowledge it presumably reflects. Further, when an OI leads to a negative finding, it doubtless produces a feeling of relief and well-being. In fact, one research study has shown that normal lab results lead to improvement in symptoms, even when OIs are not ordered for a specific clinical reason from a doctor's point of view (Sox, Margulies and Sox 1981). Thus, a doctor's act of recommending an OI may have several meanings in a medical encounter, aside from the specific results that are obtained.

With the data gleaned from the various components of the medical history, the PE, and the results of OIs, the doctor reaches a diagnosis $(\mathrm{Dx})$, that may be provisional or confirmed. The cognitive operations involved in making a diagnosis undoubtedly are complex and poorly understood. Essentially the doctor takes the patients' comments in the medical history, observations made during the $\mathrm{PE}$, and data from OIs, and shapes this information into one or more diagnostic categories.

The drive to reach a diagnosis is extremely strong. Practitioners and doctors in training view the facility of diagnostic categorization as one of the most important professional skills in medicine. The "differential diagnosis" involves a list of all possible categories into which a patient's physical problems might fall. Most practitioners would acknowledge that the tendencies to interrupt, cut off, or otherwise redirect the patient's story during the PI derive at least partly from the drive to make a diagnosis. That is, a doctor wants to hear those words that are consistent with previously defined diagnostic categories. Parts of patients' stories that do not fit neatly into these categories function as unwanted strangers in medical discourse and tend to be shown to the door (Beckman and Frankel 1984; West 1984).

While the drive to make a diagnosis is strong, diagnostic reasoning tends to be both limited and exclusionary. True, doctors and doctors-in-training must learn to deal with an awesome number of diagnostic categories and subcategories. Yet this set of diagnoses corresponds to no more than a tiny fraction of human experience. In large part, the cognitive process of reaching a diagnosis involves excluding a substantial part of a patient's experience that-no matter how relevant to the patient-is not relevant to the diagnosis. Features of patients' social context may be very troubling to patients and actually may affect their physical conditions in fairly direct ways. These contextual issues, however, are almost always difficult to define with precision, are loaded with ambiguity, and are not completely consistent with the technical categories of differential diagnosis. The exclusionary drive, so much a part of reaching a medically proper diagnosis, profoundly affects what is spoken and recorded during medical encounters. Contextual concerns that do not lend themselves to the technical lexicon of diagnostic possibilities tend to gravitate toward the margins of medical talk.

The medical plan (P) constitutes the interventions that the doctor suggests, usually toward the end of an encounter. Traditional teaching about the medical plan holds that it contains two components. First, there is a diagnostic plan, which involves the OIs that the doctor wishes to obtain after the present encounter ends. Second, in the therapeutic plan, the doctor recommends the medication, surgery, diet, rest, exercise, counselling, relaxation, attitude change, and so forth that he or she believes the patient's diagnosis warrants. A substantial part of medical education involves learning and keeping up 
with current vogues of preferred diagnostic and therapeutic plans.

Just as it affects diagnostic reasoning, the exclusionary drive also shapes the plan that is formulated. Among the infinitely varied possibilities for human action, the limited range of medical diagnoses encourages relatively few options. Usually these options involve OIs that create more technical data, or treatments that use medication, surgery, or similar technical intervention. Alternatively, a doctor may suggest nonintervention, which involves reassurance that a problem is not serious enough to require technical action, or a schedule of follow-up to be sure that the problem does not become worse. Sometimes, a doctor recommends other maneuvers such as dietary improvement, changes in habits such as smoking and alcohol consumption, counselling, psychotherapy, or behavioral change. In such situations, the problems under consideration often have roots in the social context of the encounter.

Partly because the medical diagnosis rarely provides a technical name for such contextual problems, the plan does not generally call for a contextual intervention. Instead, the medical plan tends to accept the social context as a given. Even the limited behavioral changes that doctors may encourage generally aim at a patient's less troublesome reconciliation with his or her context, rather than change in the context itself. For the medical plan, given the power and limits of the diagnostic process, the range of the possible becomes quite restricted.

Where does giving information to the patient fit in the traditional format of the medical encounter? Remarkably, this format - as taught to generations of doctors in training-lacks a specific niche for providing information. It is probably for this reason that giving information has often been catch-ascatch-can in medicine. Similarly, the absence of a specific place to give information in the encounter's format doubtless has contributed to the very problematic deficiencies and dissatisfactions that have arisen in this arena (Waitzkin 1984, 1985). Suffice it to say, the traditional format also does not guide the doctor in communicating information about contextual issues.

\section{BENEATH THE TRADITIONAL FORMAT: PROCESSING IDEOLOGY AND CONTEXT}

By questioning, by interrupting, and by otherwise shifting the direction of conversation from nontechnical problems to technical ones, doctors exclude certain topics from talk and include others. Of particular interest here are the verbal techniques that divert attention from sources of personal distress in the social context. Such techniques cut off the possibility of considering the context critically, let alone changing it. How medical encounters convey ideologic messages, and how they invoke social control, sometimes involve doctors' explicit pronouncements about what patients should or should not do. It is also likely that ideology and social control emerge from what doctors and patients exclude from their talk, and how it comes to be excluded.

Several studies of communication in medicine have suggested that medical encounters contain common structural features. In a sociolinguistic analysis of doctor-patient conversations, West has found typical "troubles" that arise in encounters (1984). When patients express concerns about events in their lives that are not amenable to doctors' technical intervention, West argues, questions and interruptions are mechanisms by which doctors steer patients', concerns back to a technical track. As West notes, other studies also have observed that doctors interrupt patients frequently and initiate more questions than patients do (Beckman and Frankel 1984; Fisher 1986; Fisher and Todd 1983; Frankel 1986). In West's tape-recorded sample of medical interactions, male doctors tended to interrupt patients more often than did female doctors. West interprets interruptions and frequent questioning as gestures of dominance, by which doctors control the flow of conversation. She also postulates a connection between social power and sexual differences in language use, in conversations generally, and more specifically in professional-client encounters:

Further, in his study of medical encounters, Mishler demonstrates how medical discourse cuts off contextual issues and redirects the focus to technical concerns (1984). Mishler presents detailed transcripts from recordings of doctor-patient communication (Waitzkin 1985) and describes two "voices" that compete with each other. The "voice of 
medicine" involves the technical topics (of physiology, pathology, pharmacology, and so forth) which concern doctors in their professional work. Alternatively, the "voice of the lifeworld" comprises the everyday, largely nontechnical problems that patients carry with them into the medical encounter. According to Mishler's analysis of transcripts, patients often try to raise contextual issues through the voice of the lifeworld. Doctors, however, are ill-equipped to deal with such issues and therefore repeatedly return to the voice of medicine. For instance, patients raise personal troubles that do not pertain to technical problems. Or, although related to technical problems, these personal troubles do not seem amenable to technical solutions. Or, the raising of personal troubles leads to discomfort for the professional, the client, or both. Under these circumstances, doctors typically introject questions, interrupt, or otherwise change the topic, to return to the voice of medicine.

Although Mishler's approach conveys how medical language encourages the saying of some things and the leaving unsaid of others, the "lifeworld" remains rather general. Mishler implies that patients' concerns about contextual issues in the lifeworld are very important to them and that cutting off these concerns is undesirable. When the voice of medicine gains sway, however, this achievement also has much to do with ideology and social control. Diverting critical attention away from the lifeworld, doctors subtly reinforce the ideas that pattern the lifeworld and may help win acquiescence to those features of the lifeworld that patients find most disconcerting. In short, a re-reading of Mishler's materials might emphasize that the voice of medicine not only tends to suppress the voice of the lifeworld but also reinforces the reasonableness and acceptability of the lifeworld in its present form.

What is left silent, unsaid, or hidden in medical encounters has fascinated other researchers, who have interpreted rich textual materials but with little or no contextual theory. Eor instance, Katz provides an extensive account of the "silent world" of the doctor-patient relationship (1984). He shows how medical language overlooks or downplays some important features of doctors' and patients' experience. Thus, Katz argues, doctors often gloss over their patients' concerns, and patients tend to leave these concerns unsaid. In Katz's account, doctors and patients tend to remain silent about many topics, especially those that would require patients' informed consent. Similarly, Cassell interprets the confusions, misunderstandings, insensitivities, and communication lapses in transcripts of doctor-patient interaction (1985). $\mathrm{He}$ reiterates a viewpoint frequently expressed, that doctors in training should learn better communication skills to avoid such gaffes in practice. Commenting on the unsaid socioemotional content of medical encounters, Cassell urges that health practitioners pay more attention to what is excluded from conversation, as well as the reasons why.

These accounts of the unsaid in medical language do not emphasize enough the pertinence of the unsaid for the context of professional encounters. Doctors do not simply overlook or downplay or suppress patients' contextual concerns. The exclusion of social context from critical attention is a fundamental feature of medical language, a feature closely connected to ideology and social control. Inattention to social issues, especially when these issues lie behind patients' personal troubles, can never be just a matter of professional inadequacy, or the inadequacy of professional training. Instead, this lack is a basic part of what medicine is in our society.

What elements of social context help shape the ideologic content of discourse? Social class, of course, is a key contextual element. Relationships of social class are crucial parts of the context in which discourse arises and in which ideology is transmitted. To the extent that doctors and patients occupy different class positions, this class difference patterns the ideologic content of their discourse. Predictably, doctors sometimes voice explicit ideologic messages that legitimate the current class structure of society; or the transmission of ideology occurs more subtly, conveyed by the absence of criticism about class structure and its various injuries. In medical encounters, marginalization constrains an oppositional voice, perhaps that of a patient in distress, through intercuntion, cut-off, or de-emphasis. This way of looking at medical discourse provides a slightly different theoretical prism to see the same problems uncovered by sociolinguists who observe a "diffidence" of working-class patients in medical encounters, or who note contention between the "voice of medicine" and the "voice of the 
lifeworld" (Waitzkin 1985; Mishler 1984). Such observations confirm that social class relations, as an element of context, pattern ideology within discourse.

But social class is not the only contextual element that affects discourse; other crucial elements include gender, age, and race. All these contextual elements can become the basis of dominance and subordination, and they are closely linked to social class. Ideologies of gender pertain in large part to the roles men and women occupy in the family and at work. Through ideologies of gender, expectations about what men and women appropriately should and should not do enter everyday language. Arising in the context of discourse, these ideologies profoundly affect what is or can be said, what appears at the center of discourse, and what slips in at the margins. Similarly, as people age, they encounter a changing set of expectations and demands, which vary a great deal among societies. In the United States, for instance, ideologies of aging can convey the image of a trash heap, where elderly people actually or symbolically move when their productivity, or reproductivity, is used up. Other societies tend to be more lenient, or even respectful, in ideologies of aging. Ideologies of race have entered discourse whenever societies have encountered the contrast between majority and minority groups. Expressions of racial ideologies have ranged from the master-slave vernacular to the only slightly more subtle versions of modernity.

Why highlight these contextual elements here? Class, gender, age, and race are some of the contextual elements that pattern ideologic language in face-to-face discourse, as well as medical discourse. It is not enough to acknowledge that ideology may be reproduced in medical discourse; the question is how this happens. That is, in concrete examples of discourse, the critical reader needs to seek specific places where ideologic reproduction occurs, and where context impinges on discourse. I propose that these places may become apparent as part of an underlying structure that is not obvious or consciously appreciated in surface meanings. Further, I expect to find these places, at least partly, in the margins of discourse - in what is left unsaid, interrupted, cut off, or deemphasized. ${ }^{3}$
CONCLUSION: A CRITICAL THEORY OF MEDICAL DISCOURSE

Now let me turn to three summaries of actual doctor-patient encounters. Transcripts of these encounters were prepared as part of a large study of doctor-patient communication that involved random sampling from private practices and hospital outpatient departments. The encounters are summarized here because they illustrate typical patterns in the sampled interactions (Waitzkin 1985). In each encounter, doctors and patients deal with personal troubles that derive largely from broader contextual issues (cf. Mills 1959, pp. 3-24). After the summaries, I try to reorganize the elements of discourse so that an underlying structure may become apparent. Then, after reviewing the three encounters, I present a general structural view of medical discourse. The structural analysis of these particular materials also points ahead to other papers in this series, which provide the full transcripts and more detailed analyses of these and other encounters.

-A man comes to his doctor several months after a heart attack. He is depressed. His period of disability payments will expire soon, and his union is about to go on strike. His doctor tells him that he is physically able to return to work and that working will be good for his mental health. The doctor also prescribes an antidepressant and a tranquilizer.

-A woman visits her doctor because of irregularities in her heart rhythm. She complains that palpitations and shortness of breath are interfering with her ability to do housework. The doctor checks an electrocardiogram while she exercises, changes her cardiac medications, and congratulates her in her efforts to maintain a tidy household.

-A man goes to his doctor for a premarital blood test. The doctor questions him closely about his drinking problem, his smoking, his job, his family, and his plans for married life. Then the doctor encourages attendance at Alcoholics Anonymous and orders a test of liver function, in addition to the premarital blood test that the patient requested.

Figure 1 shows some structural elements of discourse in the first encounter. Seen in this way, the contextual issue of uncertain employ- 
FIGURE 1. Structural Elements of Medical Encounter with a Man Anticipating Return to Work After a Heart Attack

A: $\quad$ B: $\quad$ C:

Uncertain

employment $\longrightarrow$ Depression

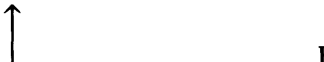

F:

Doctor encourages

patient's return to work.

- Doctor reassures that work is good for mental health.

- Doctor prescribes antidepressant and tranquilizer.
Medical

encounter

D:

Patient expresses

concern about return to work (very brief)

E:

Patient repeats concerns; doctor de-emphasizes them.

ment initially presents itself (A). Depression is a personal trouble that the patient experiences in anticipation of a return to uncertain employment (B). Coming to the medical encounter (C), the patient tentatively and briefly expresses concern about his impending return to work when his union intends to go on strike (D). He repeats these concerns at several points, but the doctor de-emphasizes them (E). Rather than pursuing the contextual problem, the doctor reassures the patient that work is good for his mental health; further, the doctor prescribes both an antidepressant medication and a tranquilizer (F). After the encounter, one assumes, the patient continues to prepare himself for a return to work.

Structural elements of the second encounter appear in Figure 2. Here the contextual issue involves expectations about women's social role in the family (A). Housework, as many have noted, is an important activity in economic "reproduction," which traditionally is the responsibility of women. Because this patient's heart symptoms interfere with her housework, she experiences emotional dis- tress (B). When she sees her doctor (C), the patient mentions this concern (D). Rather than exploring her concern in depth, the doctor does an electrocardiogram while the patient exercises (E). Based on the results, the doctor changes the patient's cardiac medications. $\mathrm{He}$ also encourages her efforts in at least trying to maintain a tidy household $(F)$. The patient thus returns to her personal challenge of doing housework in the face of serious heart disease.

Figure 3 gives some structural elements of the third encounter. This patient faces a contextual issue that derives from the patterning of role expectations that affect men (A). Like most men, this patient finds that he must hold a job steadily to support himself and his family - to use a convenient term, he must earn the "means of subsistence." Further, as he approaches marriage, he also faces an expectation that he stably perform as "head" of a family. Such expectations about work and the family, however, are not simple ones, since the patient is something of a lush. The patient therefore experiences a personal trou-

FIGURE 2. Structural Elements of Medical Encounter with a Woman Whose Heart Symptoms Interfere with Her Housework

A:

Women's role expectations (home maintenance; reproduction)

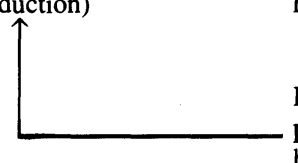

B:

Distress: heart symptoms interfere with housework

F:

Doctor encourages patient's continuing housework.

-Doctor changes patient's cardiac medications.

-Doctor encourages patient in efforts to maintain tidy household.
C:

Medical encounter

$\longleftarrow$

D:

Patient expresses concern about symptoms during housework.

E:

As patient states concern, doctor does electrocardiogram during exercise. 
FIGURE 3. Structural Elements of Medical Encounter with a Man Whose Alcohol Problem Potentially Interferes with Work and Family Relations

A:

Men's role expectations (earning means of subsistence; "head" of family)

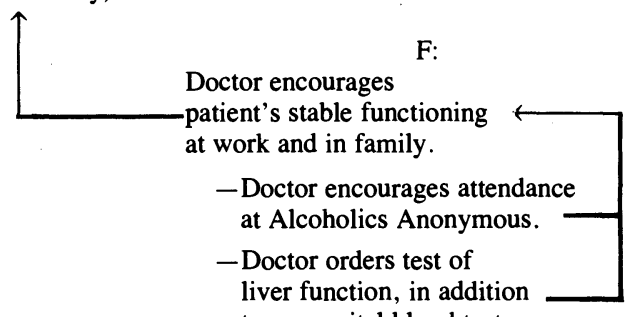

to premarital blood test.

\section{C:}

Medical

Conflicts from

alcohol use

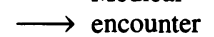

D:

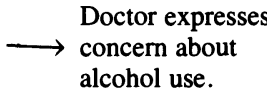

E:

Doctor questions closely about alcohol, smoking, job, family, plans for married life.

-Doctor interrupts frequently.

ble that pertains to actual or potential conflicts deriving from alcohol use (B). During the medical encounter $(C)$, the doctor takes the lead in expressing concern about alcohol (D). The doctor questions the patient closely about alcohol, as well as his heavy smoking, his job, family, and plans for married life. In pursuing these questions, the doctor interrupts the patient frequently (E). Beyond voicing strong encouragement that the patient attend Alcoholics Anonymous, the doctor also orders a test of liver function. In this discourse, the doctor encourages the patient's stable functioning at work and in the family (F).

In the paragraphs that follow, reasoning from these and other encounters, I map some islands around which medical discourse seems to flow (Figure 4). I interpret these islands as underlying structures in the flow of medical discourse, rarely discerned consciously by the doctors and patients who travel there.

A. Social issue as context: The economic, social, and political context of society contains many difficult conditions. These social issues often lie behind and help create some of the personal troubles that clients experience in their everyday lives (Mills 1959, pp. 3-24). (In the three encounters above, the pertinent social issues are: uncertain employment, women's role expectations, and men's role expectations.)

B. Personal trouble: Clients tend to experience these troubles privately, as their own individual problems. They are unlikely to recognize consciously the social issues that lie behind their personal troubles. (In the same three encounters, personal troubles include: depression, distress that heart symptoms interfere with housework, and conflicts from alcohol use.)

C. The medical encounter: Clients come to medical professionals with complaints that very often (though not always) have economic, social, and political roots. Such contextual sources of personal troubles include class structure and the organization of work; family life, gender roles, and sexuality; aging and the social role of the elderly; the patterning of leisure and substance use; and limited resources for dealing with emotional distress.

D. Expression of contextual problems in medical discourse: The traditional and technical sequence of the medical encounter does not facilitate the expression of contextual concerns. Regarding patients' own characteristics, the relations between language and social structure predictably make the expression of contextual concerns more difficult for working-class people, women, and racial minorities. Certain humanistic or progressive doctors encourage patients to talk about the nontechnical components of their problems that pertain to their lifeworlds. These patients can express concerns and vent emotions about such personal troubles. Less humanistic or progressive doctors tend to discourage patients from expressing such concerns or to ignore them when expressed.

E. Countertextual tensions deriving from social context: Contextual problems, however, create tensions in medical discourse. Periodically such tensions that derive from troubling social issues erupt into the dis- 
FIGURE 4. The Micropolitical Structure of Medical Discourse

A:

Social issue

as context

(political/

economic/

social

condition)

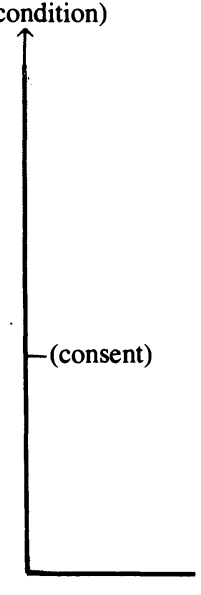

F:

Management of contextual problems

1. Offer technical solutions and counselling

2. Reproduce ideology, often conveyed through absence of criticism

3. Exclude collective action leading to social change

4. Achieve social control by encouraging consent
C:

D:

Expression of

$\longrightarrow$ contextual problems

1. Traditional, technical sequence does not facilitate

2. Sociolinguistic barriers: class, gender, minorities

3. Humanistic orientation?

a. Yes: discuss nontechnical trouble

b. No: suppress nontechnical trouble

E:

Countertextual tensions deriving from social context

1. Manifested at margins of discourse

2. May be suppressed by dominance gestures (interruptions, cut-offs, de-emphases) course, or appear at its margins, and create a countertextual reality that cannot be resolved in the framework of a medical encounter. Doctors tend to suppress such tensions by dominance gestures like interruptions, cutoffs, and de-emphases that get the discourse back on a technical track.

F. Management of contextual problems: Whether such tensions are expressed or suppressed, the language of medicine leaves few options for action. Limited options for action apply to both humanistic encounters, when doctors encourage patients to talk about nontechnical components of their personal troubles, and to less humanistic encounters, where such concerns are discouraged. Generally, doctors respond with technical solutions and counsel patients how best to adjust to their previous roles. The language of medical science can convey ideologic content, especially when it converts social problems into technical ones. Ideologic language also arises at the margins of medical discourse or achieves its impact through absence. That is, by a lack of criticism directed against sources of distress in the social context, medical discourse ideologically reinforces the status quo. The discourse of medicine thus tends to exclude basic social change as a meaningful alternative. In accepting the present context as given, and in remaining silent about collective political action, medical discourse encourages consent by rendering social change unthinkable. This latter accomplishment of medicine may be its main contribution to social control.

Further studies will show how this structure helps us understand what is happening as doctors and patients deal with problems of work, the family and gender roles, aging, sexuality, leisure, substance use, other "vices," and troublesome emotions. In addition, medical discourse in which this structure is not apparent will become a matter of particular interest.

To whatever extent this theory is persua- 
sive, other questions immediately suggest themselves: Can the structure of medical discourse be reformed? Can medical discourse include a criticism of the sources of personal distress in the social context of the professional encounter? A critical discourse in medicine, one might argue, would no longer encourage consent to contextual sources of personal troubles. By suggesting collective action as a meaningful option, medical professionals might begin to overcome the impact that its exclusion exerts. Can this be done without further medicalizing social problems? If so, critical discourse in medicine also would recognize the limits of medicine's role and the importance of building links to other forms of praxis that seek to change the social context of medical encounters. Moving beyond the current structure of medical discourse then becomes a major goal of this attempt to analyze it.

\section{NOTES}

1. Another article develops this proposition from summaries of recorded medical encounters that were randomly sampled as part of a study of doctor-patient communication (Waitzkin 1989a).

2. How this format emerged historically is a mystery (Stoeckle and Billings 1987). The preferred and widely taught sequencing of $\mathrm{CC}$ $\rightarrow \mathrm{PI} \rightarrow \mathrm{PH} \rightarrow \mathrm{FH} \rightarrow \mathrm{SH} \rightarrow \mathrm{SR} \rightarrow \mathrm{PE} \rightarrow \mathrm{OI}$ $\rightarrow \mathrm{Dx} \rightarrow \mathrm{P}$ probably goes back to late nineteenth century Europe. Many of these components appeared in textbooks of clinical medicine published in Germany during that period. While Foucault and others who have studied the history of medicine in Europe do not deal with this specific question, a similar format of the encounter presumably arose in France and Britain as well. As with most of the other features of laboratory-based "scientific" medicine, North Americans probably brought the medical encounter's format to the Eastern seaboard in the late nineteenth or early twentieth century. To what extent similarities existed between this format and those used earlier in North America is unknown. Also mysterious are the formats of medical encounters in most pre-modern societies. For instance, although much anthropologic data are available on "ethnomedical" beliefs, little is known about how encounters between so-called primitive healers and their clients are organized. What little is known indicates that some kind of history taking, physical examination, diagnostic categorization, and medical plan does appear in most ethnomedical encounters (cf. Good and Good 1981).
While elaborating the medical encounter's history and pre-history is a worthy enterprise, it is beyond my scope here and there is little doubt that the traditional format is now commonplace in many or most human societies. That this particular format should have arisen is remarkable partly because its effectiveness in improving medical conditions is so unproven. Like many other aspects of modern medicine, the beneficial impact of the medical encounter's organization on the morbidity and mortality of large populations, as well as individual patients, is difficult or impossible to demonstrate (Waitzkin 1983, pp. 3-43; McKeown 1979). This is not to deny that modern medicine has accomplished great things. Many of the medical encounter's most timeconsuming and thus costly components (such as the FH, SR, and much of the PE), however, have never been put to the test of costeffectiveness.

3. In a companion paper, I have developed these propositions further through applications of critical theory in structuralism and poststructuralism (Waitzkin 1989b).

\section{REFERENCES}

Althusser, Louis. "Ideology and Ideological State Apparatuses." 1971. Pp. 127-86 in Lenin and Philosophy and Other Essays. New York: Monthly Review Press.

Beckman, Howard B., and Richard M. Frankel. 1984. "The Effect of Physician Behavior on the Collection of Data." Annals of Internal Medicine 101:692-696.

Brown, E. Richard. 1979. Rockefeller Medicine Men. Berkeley: University of California Press.

Cassell, Eric J. 1985. Talking With Patients, 2 volumes. Cambridge: MIT Press.

Conrad, Peter. 1975. "The Discovery of Hyperkinesis: Notes on the Medicalization of Deviant Behavior." Social Problems 23:12-21.

Conrad, Peter, and J.W. Schneider. 1980. Deviance and Medicalization: From Badness to Sickness. St. Louis: Mosby.

Ehrenreich, Barbara, and John Ehrenreich. 1978. "Medicine and Social Control." Pp. 39-79 in The Cultural Crisis of Modern Medicine, edited by John Ehrenreich. New York: Monthly Review Press.

Ehrenreich, Barbara, and Deirdre English. 1973. Complaints and Disorders: The Sexual Politics of Sickness. Old Westbury, NY: Feminist Press. . 1978. For Her Own Good. New York: Anchor/Doubleday.

Engels, Friedrich. 1891 [1942]. The Origin of the Family, Private Property and the State. New York: International.

Fisher, Sue. 1986. In the Patient's Best Interest. New Brunswick, N.J.: Rutgers University Press. 
Fisher, Sue, and Alexandria Dundas Todd, eds. 1983. The Social Organization of DoctorPatient Communication. Washington, D.C.: Center for Applied Linguistics.

Foucault, Michel. 1975. The Birth of the Clinic: An Archaeology of Medical Perception. New York: Vintage. 1977. Discipline and Punish. New York: Pantheon.

1978. The History of Sexuality, volume 1. New York: Pantheon, 1978.

1980. Power/Knowledge: Selected Interviews and Other Writings. New York: Pantheon.

Fox, Renée C. 1977. "The Medicalization and Demedicalization of American Society," Daedalus 106:9-22.

Franco-Agudelo, Saul. 1983. "The Rockefeller Foundation's Anti-Malarial Program in Latin America." International Journal of Health Services 13:51-57.

Frankel, Richard M. 1986. "Talking in Interviews: A Dispreference for Patient-Initiated Questions in Physician-Patient Encounters," in Interaction Competence, edited by George Psathas. Norwood, N.J.: Ablex.

Good, Byron J., and Mary-Jo Delvecchio Good. 1981. "The Meaning of Symptoms: A Cultural Hermeneutic Model for Clinical Practice." Pp. 165-96 in The Relevance of Social Science for Medicine, edited by Leon Eisenberg and Arthur Kleinman. Boston: Reidel.

Gramsci, Antonio. 1971. Prison Notebooks New York: International.

Habermas, Juergen. 1970. "Technology and Science as 'Ideology.' " Pp. 81-122 in Toward a Rational Society. Boston: Beacon.

1971. Knowledge and Human Interests. Boston: Beacon.

Beacon.

1974. Theory and Practice. Boston:

1975. Legitimation Crisis. Boston: Beacon.

1985. The Theory of Communicative Action, Volume One: Reason and the Rationalization of Society. Boston: Beacon.

Illich, Ivan. 1975. Medical Nemesis. London: Calder \& Boyars.

Jameson, Frederic. 1971a. "The Case for George Lukacs." Pp. 160-205 in Marxism and Form. Princeton: Princeton University Press.

1971b. Marxism and Form. Princeton: Princeton University Press.

1981. The Political Unconscious: Narrative as a Socially Symbolic Act. Ithaca: Cornell University Press.

Katz, Jay. 1984. The Silent World of Doctor and Patient. New York: Free Press.

Kelman, Sander. 1975. "The Social Nature of the Definition Problem in Health." International Journal of Health Services 5:625-642.

Knorr-Cetina, Karin, and Aaron V. Cicourel, eds.
1981. Advances in Social Theory and Methodology: Toward an Integration of Micro- and Macro-Sociologies. Boston: Routledge \& Kegan Paul.

Lukacs, George. 1971a. History and Class Consciousness. Cambridge: MIT Press.

1971b. The Theory of the Novel. Cambridge: MIT Press.

Marx, Karl, 1894 [1971]. Capital, volume 3. Moscow: Progress Publishers.

Marx, Karl, and Friedrich Engels. 1846 [1939]. The German Ideology. New York: International.

McKeown, Thomas. 1979. The Role of Medicine: Dream, Mirage, or Nemesis? Princeton: Princeton University Press.

Mills, C. Wright. 1959. The Sociological Imagination. New York: Oxford University Press.

Mishler, Elliot G. 1984. The Discourse of Medicine: Dialectics of Medical Interviews. Norwood, N.J.: Ablex.

Poster, Mark. 1984. Foucault, Marxism, and History. New York: Basil Blackwell.

Sox, Harold C., Iris Margulies, and Carol Hill Sox. 1981. "Psychologically Mediated Effects of Diagnostic Tests." New England Journal of Medicine 95:680-85.

Stoeckle, John D., and J. Andrew Billings. 1987. "A History of History-taking: the Medical Interview." Journal of General Internal Medicine 2:119-27.

Taussig, Michael T. 1980. "Reification and the Consciousness of the Patient." Social Science \& Medicine 14B:3-13.

Waitzkin, Howard. 1971. "Latent Functions of the Sick Role in Various Institutional Settings." Social Science \& Medicine 5:45-75.

1978. "The Informative Process in Medical Care: Terminal Progress Report." Submitted to National Center for Health Services Research (HS-02100, Working Paper \#32).

1983. The Second Sickness: Contradictions of Capitalist Health Care. New York: Free Press.

1984. "Doctor-Patient Communication: Clinical Implications of Social Scientific Research." Journal of the American Medical Association 252:2441-46.

1985. "Information Giving in Medical Care." Journal of Health and Social Behavior 26:81-101.

1989a. "A Critical Theory of Medical Discourse: How Health Professionals Deal With Social Problems." International Journal of Health Services. Forthcoming.

1989b. "A Critical Theory of Medical Discourse: Text, Context, and the Structure of Medical Encounters." In Current Research on Occupations and Professions, forthcoming.

Waitzkin, Howard, and John D. Stoeckle. 1972. "The Communication of Information About 
Illness: Clinical, Sociological, and Methodological Considerations." Advances in Psychosomatic Medicine 8:180-215.

1976. "Information Control and the Micropolitics of Health Care." Social Science \& Medicine 10:263-76.

Waitzkin, Howard, and Barbara Waterman. 1974. The Exploitation of Illness in Capitalist Society. Indianapolis: Bobbs-Merrill.

Weinstein, Milton C. and William B. Stason. 1977. "Foundations of Cost-Effectiveness Analysis for Health and Medical Practices." New England Journal of Medicine 296:716-721.

West, Candace. 1984. Routine Complications: Troubles With Talk Between Doctors and Patients. Bloomington: Indiana University Press.
Ziem, Grace. 1977. "Medical Education Since Flexner," Health/PAC Bulletin 76:8-14, 23.

Zola, Irving Kenneth. 1972. "Medicine as an Institution of Social Control." Sociological Review 20:487-504.

1975. "In the Name of Health and Illness:

On Some Socio-political Consequences of Medical Influence." Social Science \& Medicine 9:83-87.

1983. "The Medicalizing of Society." Pp.

243-96 in Socio-Medical Inquiries. Philadelphia: Temple Üniversity Press.

Zuckerman, A., B. Starifelù, C. Hochreiter, and B. Kovasznay. 1975. "Validating the Content of Pediatric Outpatient Medical Records by Means of Tape Recording Doctor-Patient Encounters." Pediatrics 56:407-11.

HOWARD WAITZKIN is Professor of Medicine and Social Sciences, and Chief of the Division of General Internal Medicine and Primary Care, at the University of California, Irvine. His research interests focus on doctor-patient communication and health policy. Currently, he is finishing a book, tentatively titled At the Margins of Medicine: A Critical Study of How Patients and Doctors Deal With Social Problems (Yale University Press, Forthcoming). 